\title{
Aberration corrected STEM and High Resolution EELS study Investigating Magnesium Intercalation in Vanadium Pentoxide Cathode
}

\author{
Arijita Mukherjee ${ }^{1}$, Niya $\mathrm{Sa}^{2}$, P J Phillips ${ }^{1}$, Justin Andrews ${ }^{3}$, Sarbajit Banerjee ${ }^{3}$, A K Burrell ${ }^{2}$, R F Klie ${ }^{1}$ \\ 1. Department Of Physics, University Of Illinois At Chicago, 845 West Taylor Street, Chicago, Illinois \\ 60607,United States \\ 2. Chemical Sciences and Engineering Division, Argonne National Laboratory, 9700 S Cass Avenue, \\ Lemont, Illinois 60439, United States \\ 3. Department Of Chemistry, Texas A\&M University, Ross Street, College Station, Texas 77840
}

Magnesium ion based batteries hold promise as a competitive alternative to conventional Lithium ion battery technology due to several key features. Theoretical volumetric capacity for magnesium metal anode is much higher compared to lithium metal. Furthermore, $\mathrm{Mg}$ is more readily available compared to $\mathrm{Li}$, which can potentially lead to cost reduction and switching to $\mathrm{Mg}$ offers safety benefits over Li as well. Orthorhombic $\mathrm{V}_{2} \mathrm{O}_{5}$ is a well-known intercalation cathode host for $\mathrm{Mg}$-ion batteries owing to its characteristic layered structure and weak vanadium oxygen bonding that facilitates ion intercalation between the layers.

The following contribution will focus on systematic characterization of electrochemically cycled thin film orthorhombic $\mathrm{V}_{2} \mathrm{O}_{5}$ cathode host to verify $\mathrm{Mg}$ intercalation employing aberration corrected scanning transmission electron microscopy (STEM) imaging. Our results indicate that upon electrochemical cycling the $\varepsilon$-phase is formed in agreement with previous density functional theory calculations. ${ }^{[1][2]}$ This is remarkably different from the $\delta$-phase which is commonly observed in direct solid state synthesis of $\mathrm{MgV}_{2} \mathrm{O}_{5}$. Though the intercalation levels are low (which is possibly because the formation of fully magnesiated delta phase would involve structural rearrangement requiring high interfacial energy leading to low rates), this study aims to directly probe the $\mathrm{Mg}$ intercalation sites in orthorhombic $\mathrm{V}_{2} \mathrm{O}_{5}$, which is predicted to be one of the "beyond chevrel" phase high-voltage cathode host for $\mathrm{Mg}$ ion batteries. Multislice image simulations using the Kirkland code were also performed for the $\varepsilon-\mathrm{Mg}_{\mathrm{x}} \mathrm{V}_{2} \mathrm{O}_{5}$ crystal in [001] orientation which closely matches our experimental data as well. Figure 1(a) and 1(b) present atomic resolution high angle annular dark field (HAADF) and Annular Bright field (ABF) images respectively for the cycled thin film orthorhombic $\mathrm{V}_{2} \mathrm{O}_{5}$ cathode. Simulated results of HAADF and ABF images are also shown in Fig 1(c) and Fig 1(d) respectively. The structural model for the electrochemically cycled $\varepsilon-$ $\mathrm{Mg}_{\mathrm{x}} \mathrm{V}_{2} \mathrm{O}_{5}$ phase is shown in Fig 1(e) while the structure for chemically synthesized $\delta-\mathrm{MgV}_{2} \mathrm{O}_{5}$ is presented in Fig 1(f).

It was also recently reported that a new tunnel-structured polymorph of $\mathrm{V}_{2} \mathrm{O}_{5}\left(\zeta-\mathrm{V}_{2} \mathrm{O}_{5}\right)$ has been stabilized, which could serve as a better cathode host for $\mathrm{Li}$ and $\mathrm{Mg}$ intercalation due to lower band gap. ${ }^{[3]}$ Results will be presented discussing the detailed structure of the $\zeta-\mathrm{V}_{2} \mathrm{O}_{5}$ nanowire using aberration-corrected STEM imaging and electron energy loss spectroscopy (EELS) and Mg intercalation sites will be investigated in these $\zeta-\mathrm{V}_{2} \mathrm{O}_{5}$ nanowires after electrochemical cycling as well. In addition, the chemicallysynthesized $\beta-\mathrm{Mg}_{\mathrm{x}} \mathrm{V}_{2} \mathrm{O}_{5}$ nanowires will also be studied in order to compare the $\mathrm{Mg}$ intercalation sites with the electrochemically cycled $\zeta-\mathrm{V}_{2} \mathrm{O}_{5}$. Figure 2(a) presents atomic-resolution HAADF image for $\zeta_{-}-\mathrm{V}_{2} \mathrm{O}_{5}$ nanowires clearly showing the tunnel structure geometry [as shown by the structure in Fig 2(b)] and the EELS spectra [shown in Fig 2(c)] verifies the valence state of vanadium as $\mathrm{V}^{5+}$ (by comparing the energy difference between $\mathrm{V} \mathrm{L}_{3^{-}}$and $\mathrm{O} K$ - edge onset) as expected. ${ }^{[4]}$ 
References

[1] G S Gautam et al, The Intercalation Phase Diagram of $\mathrm{Mg}$ in $\mathrm{V}_{2} \mathrm{O}_{5}$ from First Principles, Chem Mat, 2015, 10,1021

[2] A. Mukherjee, N.Sa, P J Phillips, A Burrell, R F Klie, Investigation of Mg intercalation into thin film orthorhombic $\mathrm{V}_{2} \mathrm{O}_{5}$ cathode using Aberration corrected STEM and EELS [Manuscript in preparation]

[3] P.M Marley et al, Emptying and Filling a Tunnel Bronze, Chem. Sci, 2015, 6, 1712

[4] This work is supported by the Joint Center for Energy Storage Research (JCESR), an Energy

Innovation Hub funded by the U.S. Department of Energy (DOE), Office of Science, Basic Energy

Sciences.
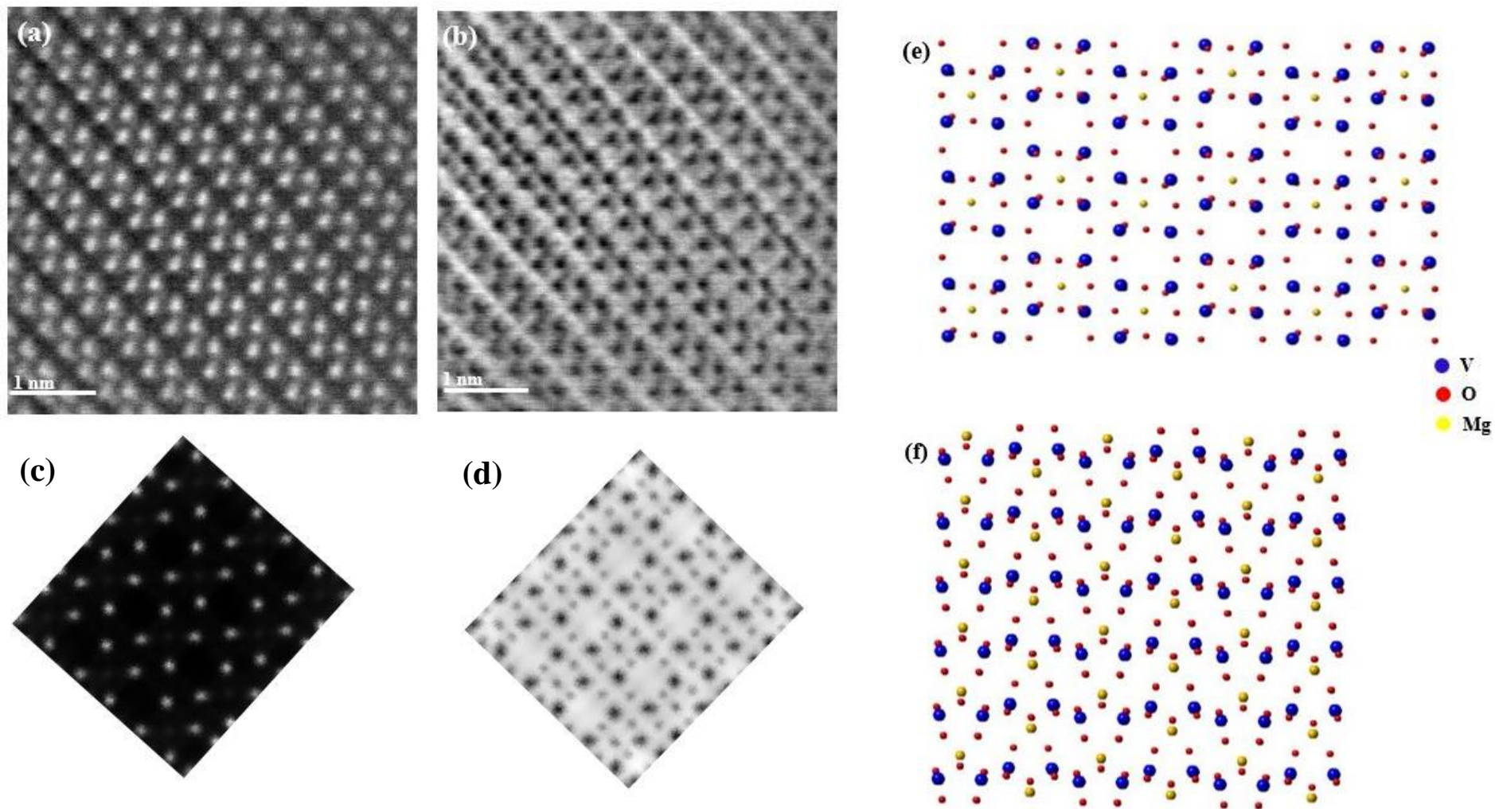

Figure 1:(a) Filtered atomic-resolution HAADF image and (b)Filtered ABF image(c) Multislice image simulation of HAADF image and (d)ABF image for $\varepsilon-\mathrm{Mg}_{\mathrm{x}} \mathrm{V}_{2} \mathrm{O}_{5}$ crystal along [001] zone (e) $\varepsilon-\mathrm{Mg}_{\mathrm{x}} \mathrm{V}_{2} \mathrm{O}_{5}$ and (f) $\delta-\mathrm{MgV}_{2} \mathrm{O}_{5}$ structure.
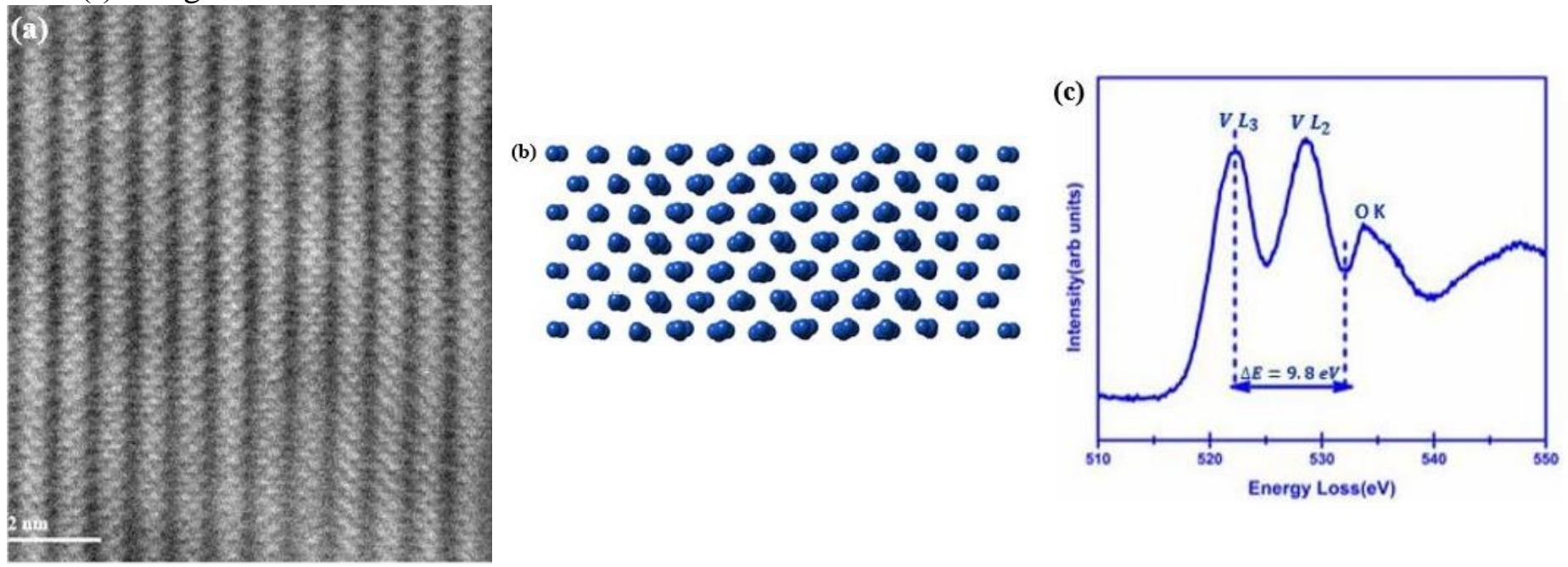

Figure 2:(a) Atomic resolution(filtered) HAADF image of $\zeta-\mathrm{V}_{2} \mathrm{O}_{5}$ nanowire and (b) $\zeta-\mathrm{V}_{2} \mathrm{O}_{5}$ structure showing only $\mathrm{V}$ atoms (c) EELS spectra from $\zeta-\mathrm{V}_{2} \mathrm{O}_{5}$ nanowire 